\title{
Assessment of the Prevalence of Diarrheal Disease Under-five Children Serbo Town, Jimma Zone South West Ethiopia
}

Legefa Futa Kasee ${ }^{1}$, Oeegus Samba Merrom ${ }^{*}$ and Hengistu Yyele Hassa ${ }^{2}$

${ }^{1}$ Department of Medicine, Institute of Health science, Jimma University, Jimma, Ethiopia

${ }^{2}$ Department of Biomedical Sciences, Anatomy Course Team, Jimma University, Jimma, Ethiopia

*Corresponding author: Merrom OS, College of Health Sciences, Department of Biomedical Sciences, Anatomy Course Team, Jimma University, Jimma, Ethiopia, Email: moti10m@gmail.com

Received date: December 15, 2017; Accepted date: January 05, 2018; Published date: January 08, 2018

Copyright: (2018 Kasye GG, et al. This is an open-access article distributed under the terms of the Creative Commons Attribution License, which permits unrestricted use, distribution, and reproduction in any medium, provided the original author and source are credited.

\begin{abstract}
Background: Although there is global decline in the death rates of children younger than 5 years old, the risk of a child dying before becoming 5 years of age remains highest in the WHO African Region (90 per 1000 live births). The highest rates of child mortality are seen in sub-Saharan Africa, where 1 in 8 children dies before age 5 , more than 17 times the average for developed regions. The problem of child death in Ethiopia is worse, with an Ethiopian child being 30 times more likely to die by his/her fifth birthday than a child in Western Europe. Therefore, the aim of this study was to assess the prevalence and factors associated with diarrhoea among children younger than five years old.
\end{abstract}

Objective: The objective of this study was to measure the prevalence of diarrhoea and its associated factors among children under-five years of age in Serbo town in Jimma zone, Ethiopia.

Methods: A community-based, cross-sectional study was conducted on children younger than five years old from June to July 2017. A total of 250 under-five children were included in this study, and subjects were recruited by the multistage cluster sampling technique. Data were collected by a pre-tested questionnaire. The data were coded, entered, cleaned and analyzed the SPSS software package version 24.

Result: The prevalence of childhood diarrhoea was $14.9 \%(n=26)$ high rate in under 2 years and no sex variation. The proportion of acute watery diarrhoea was $92.3 \%(n=24)$ of those children $76.9 \%(n=20)$ were treated in health institution. The age care takers was assessed and those $20-39$ years of age had the highest rate $65.4 \%(n=17)$ of the two weeks diarrhoea prevalence. Mothers of children who had completed 1-6 grade had the highest rate 11 $(42.3 \%)$ of two weeks diarrhoea prevalence.

Conclusion: In this study, prevalence of diarrhoea among under-five children was quite high. The highest rate of the prevalence was significantly concentrated among children aged 20-29 $(40.1 \%)$ months. The age of child, educational level of mothers, and the economic status of households were the most important variables that affected the occurrence of diarrhoea in children.

Keywords: Childhood diarrhoea; Under-five children; Socioeconomic factors; Serbo community

\section{Introduction}

Although there is global decline in the death rates of children younger than 5 years old, the risk of a child dying before becoming 5 years of age remains highest in the WHO African Region (90 per 1000 live births), which is approximately seven times higher than that in the WH O European Region (12 per 1000 live births) [1].

Children in developing countries are disproportionately affected by preventable and treatable diseases with simple and affordable interventions. Every day more than 4000 children lose their life due to diarrhoea [2]. The vast majority of these deaths are among children who live in low-and middle-income countries [3]. In Ethiopia, the 2010 report of the Ministry of Finance and Economic Development (MOFED) indicated that $20 \%$ of childhood deaths in the country were due to diarrhoea. The 2011 Demographic and Health Survey of
Ethiopia (EDHS) findings also showed that $13 \%$ of the children had diarrhoea in the 2 weeks preceding the survey at the national level $[4,5]$.

Diarrhoea is generally defined as three or more loose or watery stools within a $24 \mathrm{~h}$ period [6-8], or a decrease in the consistency of the stool from that which is normal for the patient [9].

In developing countries, diarrhoea is most often a symptom of gastrointestinal infection caused by bacteria, viruses or parasites which are commonly transmitted via the faecal-oral route, where the pathogens are excreted from the intestinal tract of a person or animal carrying the illness and are ingested by another [9].

People in the economically poorest regions of the world and the least developed countries continue to bear the heaviest burden of child deaths. More than four-fifths of all deaths among children younger than 5 years old in 2011 occurred in sub-Saharan Africa and South Asia [10]. Diarrhoeal disease is not purely medical, but huge part of this should be traced back to the social, economic, environmental and 
Page 2 of 6

behavioural aspects of the family. The problem in Ethiopia is even worse than elsewhere in the world, with an Ethiopian child being 30 times more likely to die by his/her fifth birthday than a child in Western Europe [11]. Studies conducted in Ethiopia, in other regions documented many socioeconomic factors such as overcrowding and low maternal education, poor sanitation, contaminated water, failure to continue breast feeding until one year of age, using infant bottles which are difficult to clean, storing food at room temperature, failure to wash hands, failure to dispose of faeces hygienically and inadequate food hygiene were associated with a high incidence of under-five diarrheal diseases [12-21].

\section{Methods and Materials}

\section{Study design and setting}

A community-based cross-sectional study was conducted among mothers with children younger than 5 years old from June to July, 2017 in Serbo town. It is located $354 \mathrm{~km}$ away from the capital city Addis Ababa, Jimma zone, Oromia Region, South west Ethiopia.

\section{Sample size determination and sampling technique}

The sample size was determined using the single population proportion formula, $\mathrm{ni}=(\mathrm{Za} / 2) 2 \mathrm{p}(1-\mathrm{p}) / \mathrm{d} 2, \mathrm{ni}=(1.96-/ 2) 0.5(1-0.5)$ $\mathrm{n}=$ minimum sample size required $0.052 \mathrm{P}=0.5$.

d-The margin of sampling error tolerated $(0.05)=384$

$\mathrm{z}-/ 2$ the standard normal variable at (1-) 1 confidence level and is mostly 5\% i.e., with a $95 \%$ confidence level 196 the rate was corrected by using the following method.

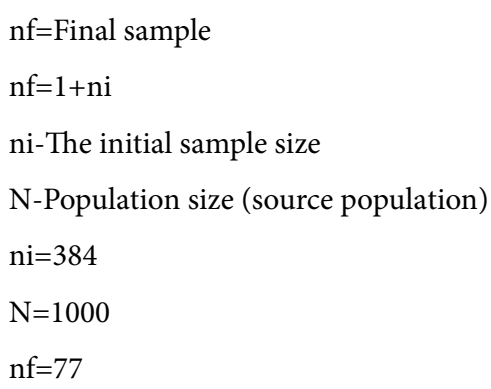

However, the number of children less than five in the area is less than 10,000 and we used correction formula to calculate the actual sample size. Thus, we had 277 study participants in the beginning of our study.

\section{Sampling technique}

After the sample size determined as above systematic random sampling method employed to draw sample from the target population assuming one under five children per house hold expected to be sampling interval determined by using $\mathrm{K}=\mathrm{N} / \mathrm{nf}$.

Thus a sample interval for children under 5 years was every 4 house hold expected to be sampling interval determined by using.

After the sample size was determined, systematic random sampling method was employed to draw sample from the target population. The first household was selected by lottery method and the next house was systematically selected in every 4 house interval. When children under five years are more than one in the sampled house hold one child was chosen using lottery method.

\section{Data collection and procedure}

A structured questionnaire containing close ended questions was administered to mothers/care givers who have children younger than 5 years old to collect information on age of mother's and child; sex of child; Ethnicity, religions and educational status of the mothers/care givers. Awareness of mothers on type of diarrhoea, type of care given for children with diarrhoea and risk factors for diarrheal disease were assessed. The questionnaire was prepared in English language and translated to the local language by a person who was blind to the study. Instruments were pre tested prior to data collection with almost $5 \%$ of children found in the near city. Then, all modifications were made and the actual data collection started later. The data were collected by trained health personnel's who had experience in data collection and data managements. Data completeness was checked by principal investigator on daily base at the end of each data collection day.

\section{Data analysis and presentation}

Data analysis was performed by using SPSS version 24 for windows. Descriptive statistics were applied to show frequency and percentages.

\section{Results}

Out of 277 sampled mothers or care givers for children, only 250 of them were gave their response voluntarily. From the total 250 study participants, $70 \%$ of the participants were mothers, $10 \%$ were fathers and $20 \%$ were other care givers of the children in the family. The general socio-demographic characteristics of the respondents; majority of respondents 101 (40.4\%) were between 20-29 years, $143(56.8 \%)$ were Oromo, 80 (32.4\%) Muslim, 76 (30 \%) were completed grade 5-8, $143(57.2 \%)$ of them were house wife and $82(32.8 \%)$ were earns 501-700 ETB per month (Table 1).

\begin{tabular}{|c|c|c|}
\hline Characteristics & Frequency & Percent (\%) \\
\hline \multicolumn{3}{|l|}{ Age } \\
\hline$<20$ & 43 & 17.2 \\
\hline $20-29$ & 101 & 40.4 \\
\hline $30-39$ & 55 & 22 \\
\hline $40-49$ & 3 & 14.4 \\
\hline$>49$ & 15 & 6 \\
\hline Total & 250 & 100 \\
\hline \multicolumn{3}{|l|}{ Ethnicity } \\
\hline Oromo & 142 & 56.8 \\
\hline Amhara & 78 & 31.2 \\
\hline Garage & 17 & 6.8 \\
\hline Others & 13 & 5.2 \\
\hline Total & 250 & 100 \\
\hline Religion & & \\
\hline
\end{tabular}


Citation: Kasye DG, Garoma NH, Kassa MA (2018) Assessment of the Prevalence of Diarrheal Disease Under-five Children Serbo Town, Jimma

Page 3 of 6

\begin{tabular}{|l|l|l|}
\hline Muslim & 126 & 50.4 \\
\hline Orthodox & 80 & 32 \\
\hline Protestant & 44 & 17.6 \\
\hline Others & - & - \\
\hline Total & 250 & 100 \\
\hline Educational status & & \\
\hline Illiterate & 40 & 16 \\
\hline Primary & 119 & 47 \\
\hline Secondary & 29 & 11.6 \\
\hline $12+$ above & 54 & 21.6 \\
\hline Total & 250 & 100 \\
\hline
\end{tabular}

\begin{tabular}{|l|l|l|l|l|l|}
\hline $24-35$ & 30 & 12 & 24 & 9.6 & 54 \\
\hline $36-47$ & 25 & 10 & 30 & 12 & 55 \\
\hline $48-59$ & 21 & 8.4 & 26 & 10.4 & 47 \\
\hline Total & 116 & 46.4 & 124 & 53.6 & 250 \\
\hline
\end{tabular}

Table 2: Socio-economic characteristics of children in Serbo town, Jimma, zone, July, 2017.

Considering the ethnicity of the care takers, the highest rate 20 (77\%) of the cases were seen among Oromo and 6 (23\%) were among Amhara. Regarding the religion the care takers of children who are Muslim had the highest rate 14 (54\%). On the other hand care takers who are Christian had the lowest rates (12-46\%) of diarrhoea prevalence.

Mothers of children who had completed 1-6 grade had the highest rate $11(42.3 \%)$ of the two-week diarrhoea prevalence; grade 7 and above had relatively lowest rate $6(23.1 \%)$ of prevalence. Illiterate mothers had relatively high rate 9 (34.4\%). There was statistically significant difference $(\mathrm{P}$-value $<0.05)$ was observed between the illiterate and literate mothers (Table 3 ).

Concerning the occupation of the mothers, house wife had the highest rate $18(69 \%)$ of the two-week diarrhoea prevalence as compared to government employee, merchant, daily (labourers) and mothers with other type of occupation (Table 3 ).

\begin{tabular}{|l|l|l|l|}
\hline \multicolumn{4}{|l|}{ Literacy status } \\
\hline Literate & $20(77 \%)$ & $90(40 \%)$ & $110(44 \%)$ \\
\hline Illiterate & $6(23 \%)$ & $134(60 \%)$ & $140(56 \%)$ \\
\hline Total & $26(100 \%)$ & $224(100 \%)$ & $250(100 \%)$ \\
\hline Occupational & \multicolumn{5}{|l|}{} \\
\hline House wife & $18(69 \%)$ & $130(58 \%)$ & $148(59 \%)$ \\
\hline Gov't employee & $2(7.7 \%)$ & $60(26.8 \%)$ & $62(25 \%)$ \\
\hline Merchants & $2(7.7 \%)$ & $25(11.4 \%)$ & $27(11 \%)$ \\
\hline Daily labourer & $4(15.4 \%)$ & $9(4 \%)$ & $13(5 \%)$ \\
\hline Total & $\begin{array}{l}26 \\
(100 \%)\end{array}$ & $224(100 \%)$ & $250(100 \%)$ \\
\hline
\end{tabular}

The age of the care takers was classified as less than 20, 20-29, 30-39, 40-49 and above 49 years. Those care takers $20-39$ years of age had the highest rate $17(65.4 \%)$ of the two weeks diarrhoea prevalence, on the other hand those mothers age greater than 49 years and less than 20 years had the lowest rate $4(15.4 \%)$ and $5(19.2 \%)$ respectively (Table 2).

\begin{tabular}{|l|l|l|l|l|l|}
\hline \multirow{2}{*}{$\begin{array}{l}\text { Age } \\
\text { months }\end{array}$} & \multicolumn{4}{|c|}{ Sex } & \multirow{2}{*}{ Total } \\
\cline { 2 - 5 } & \multicolumn{2}{|l|}{ Male } & \multicolumn{2}{|l|}{ Female } & \\
\cline { 2 - 5 } & $\begin{array}{l}\text { Frequenc } \\
\text { y }\end{array}$ & $\begin{array}{l}\text { Percent } \\
(\%)\end{array}$ & Frequency & $\begin{array}{l}\text { Percent } \\
(\%)\end{array}$ & \\
\hline $0-6$ & 12 & 4.8 & 17 & 6.8 & 29 \\
\hline $7-11$ & 8 & 3.2 & 14 & 5.6 & 22 \\
\hline $12-23$ & 20 & 8 & 23 & 9.2 & 43 \\
\hline
\end{tabular}

Table 3: Distribution of diarrheal disease prevalence by the socioeconomic one demographic characteristic of mothers/care takers/in Serbo town, Jimma zone July, 2017.

Mothers whose monthly income were between 100-300 birr had relatively high rate $11(42.3 \%)$ and similarly mothers whose monthly income were between $301-500$ had high rate 8 (30.8\%) of the cases. least rate $1(3.8 \%)$ had observed among mothers who earns greater than 701 birr (Table 3).

The type of treatment practice of care takers at home were assessed during diarrhoea attack and the majority 9 (45\%) were used ORS, 5 (25\%) were used homemade solution and $6(30 \%)$ of them were used other type of treatment among children with diarrhoea. 20 (76.9\%) were treated in health institution and out of these $16(80 \%)$ were given ORS. 


\begin{tabular}{|l|l|l|l|l|}
\hline \multirow{2}{*}{ Feeding practice } & \multicolumn{2}{|l|}{ Yes } & \multicolumn{2}{l|}{ No } \\
\cline { 2 - 5 } & No: & $\%$ & No: & $\%$ \\
\hline
\end{tabular}

\begin{tabular}{|l|l|l|l|l|}
\hline Amount of fluid offered & 12 & 46.1 & 4 & 15 \\
\hline Same of usual & 6 & 23 & - & - \\
\hline More & 6 & 15.3 & - & - \\
\hline Less & 4 & &
\end{tabular}

\section{Offered amount of food}

\begin{tabular}{|l|l|l|l|l|}
\hline Same of usual & 6 & 42.8 & 6 & 23 \\
\hline More & 5 & 35.7 & - & - \\
\hline Less & 3 & 21.4 & - & - \\
\hline Continue EBR & 13 & 92.8 & & 7.1 \\
\hline
\end{tabular}

Table 4: Feeding practice of mother/caretakers/during diarrheal disease in Serbo town, Jimma zone, July, 2017.

Among children with diarrheal disease $4(15.4 \%)$ were on breast milk alone and breast feeding was discontinues in 1 (25\%); of these children, more fluid was offered to $6(23.0 \%)$ and more food was offered to $5(35.7 \%)$ of the children with diarrhoea who were already on weaning diet. Less fluid was offered to $4(15.3 \%)$ and less food was offered to 3 (21.4\%) of these children (Table 4 ).

Major source of drinking water of the Family were assessed and the majority were $26(93 \%)$ used pipe/tap water $2(7.1 \%)$ were used protected well. when analyzed the prevalence of diarrheal disease was relatively high $(33.3 \%)$ of protected well. However still there was high rate (16.4\%) of diarrhoea cases among pipe water user (Table 5).

The prevalence of diarrhoea and availability of latrine facilities were assessed and there was no association, because all assessed have toilet. On the other hand, the proper use of latrine and refuse pit were assessed and $180(72 \%)$ have had proper use of latrine whereas only 76 (30.4\%) have had proper waste disposal and 160 (64\%) had no proper waste disposal site (Table 6).

\begin{tabular}{|c|c|c|c|c|c|}
\hline \multirow{3}{*}{$\begin{array}{l}\text { Source of drinking } \\
\text { water }\end{array}$} & \multicolumn{5}{|c|}{ Presence of diarrhea } \\
\hline & \multicolumn{2}{|c|}{ Yes } & \multicolumn{2}{|l|}{ No } & \multirow[t]{2}{*}{ Total } \\
\hline & No & $\%$ & No & $\%$ & \\
\hline Protected spring & - & - & - & - & - \\
\hline Unprotected spring & - & - & - & - & - \\
\hline Protected well & 2 & 7.1 & 24 & 10.4 & 26 \\
\hline Unprotected well & - & - & - & - & - \\
\hline Pipe tap water & 26 & 92.3 & 200 & 89.6 & 224 \\
\hline Total & 28 & 100 & 224 & 100 & 250 \\
\hline
\end{tabular}

Table 5: Distribution of households by their major source of drinking water and presence of diarrheal in Serbo town, Jimma zone, July, 2017.

\begin{tabular}{|c|c|c|c|c|}
\hline & \multicolumn{2}{|l|}{ Yes } & \multicolumn{2}{|l|}{ No } \\
\hline & & $\%$ & & $\%$ \\
\hline Use of latrine properly & 180 & 72 & 50 & 20 \\
\hline Use of garbage & 70 & 28 & 160 & 64 \\
\hline
\end{tabular}

Table 6: Distribution of the family by the use of latrine and garbage in Serbo town, Jimma zone, July 2017.

\section{Discussions}

The prime objectives of this study were to identify the prevalence of diarrheal disease among children younger than 5 years old. It was found that more than one-ninth (12\%) of the children included in the study reported diarrhoeal disease in the 2 weeks before the survey. This finding was supported by a study performed in east Gojam zone (6.5\%) [22], EDHS 2011 report (13\%), studies conducted in Egypt (19.5\%), Ghana (19.2\%), Benishngul-Gumuz (22.1\%), west Gojam zone (18\%), North Gondar zone (15\%) [23] and eastern Ethiopia Kersa district (22.5\%) [24-29], Arba-Minch rural community (31\%) [30], 15\% in Keffa Sheka Zone of SouthernEthiopia, 18\% in Mecha District of Northwest Ethiopia, 22.5\% Kersa district of Western Ethiopia 18\% and 13.5\%, in 2011 report of EDHS, respectively [31-35]. The current finding was also in agreement with studies conducted in Nakemet, Western Ethiopia, and Jigjiga District, Somali Region, Eastern Ethiopia, where the rates of diarrhoea among children younger than 5 years old in these two regions were $28.9 \%$ and $27.3 \%$ respectively. However, the current finding was higher than the finding in east Gojam zone, Amhara region (6.5\%) [22]. However, the current findings were lower than those of similar studies conducted in rural households in Northwestern Burundi, where the prevalence of diarrhoea was $32.6 \%$, similar studies conducted in Egypt (19.5\%), Ghana (19.2\%), Benishngul-Gumuz (22.1\%) west Gojam zone (18\%), North Gondar zone (15\%) [23] and eastern Ethiopia Kersa district (22.5\%) [24-29].

The educational status of the mother/care taker in this study grade 12 and above is 54 (21.6\%). Mothers with higher education experienced better chance of a child being saved from diarrhoea compared to mothers with lower educational status which is in line with studies done in Benishangul-Gumuz [36], west Gojam zone [37] and south west Ethiopia rural community [38], Iraq [39], Ghana [40], This is most likely due to education gives important information about personal and environmental hygiene, weaning and feeding practices. Mothers' level of education may help to access health care information and may have an awareness of diarrhoea prevention and control.

Another predictor variables of diarrhoea under five children found in this study was age of child. Children whose age was greater than 24-35 months (12\%) were at high risk of developing diarrhoea when compared with children whose age was less than. This may due to the 
introduction of contaminated weaning foods, starting of crawling, risk of ingesting contaminated materials, and loss of inborn immunity may increase the prevalence of diarrhoea. This was in line with study conducted in North West, Southern and Eastern Ethiopia [31,32,39].

The source of drinking water is one of the major factor for determine the prevalence of diarrheal disease under five children. In this study $92.3 \%$ use pipe tap water and $7.7 \%$ protected well. Children from households who use better water source were less vulnerable to experience diarrhoea compared to children from households who use unimproved water source which is in line with studies done in west Gojam zone [37], and case control study in Derashe district [40]. This is can be due to using improved (protected well) water source have a tendency to be less contaminated by pathogenic microorganisms than unimproved water source and thus decrease diarrhoea under-five children [41-43].

Another major predictor variables of diarrhoea under five children found in this study was latrine availability and use of latrine properly (72\%). The risk of having diarrhoea was found to be significantly associated with latrine facility, where children living in houses without latrine facilities were most likely have high risk of diarrheal than children living in households with latrine facilities, this study contradict with the study in Ghana, western, southern and northwest Ethiopia [29,39,44-46]. Because this has an important implication that the simple presence of latrine facility does not have a great contribution for prevention of excreta-related disease but it is the proper utilization that had a vital importance. In this study majority (72\%) of the household had unimproved type of latrine which serves as for the breeding of flies and increase the risk of diarrhoea than those used open field. Because this unimproved type of latrine found near the living room and the child exposed for diarrhoea causing pathogens during playing and the flies contaminate food and drinking water at household [47-49].

\section{Conclusion}

The prevalence of diarrhoea among under-five children in Serbo town Jimma zone was quite high. The highest rate of the prevalence was significantly concentrated among children aged 12.0-23.0 months. The childhood diarrheal disease was statistically associated with the number and age of under-five children, the educational level of mothers, and the economic status of households. To minimize the magnitude of childhood diarrheal disease, designing and implementing various prevention strategies, such as health education, child care, personal hygiene, and household sanitation, in integration with the existing national health extension program is recommended.

\section{Acknowledgement}

Our earnest gratitude goes to the administration of Serbo community, data collectors and the study participants for their cooperation. In addition, Jimma University community based education (CBE) office for the fund of the study.

\section{References}

1. World health organization (2017) Global Health Observatory (GHO). Under-five mortality.

2. PATH (2009) Diarrheal disease: solutions to defeat a global killer.

3. UNICEF (2013) Water, sanitation and hygiene annual report.
4. Nyantekyi LA, Legesse M, Belay M, Tadesse K, Manaye K (2010) Intestinal parasitic infections among under-five children and maternal awareness about the infections in Shesha Kekele, Wondo Genet, Southern Ethiopia. Ethiop J Health Dev 24: 3.

5. Dessalegn M, Kumie A, Tefera W (2011) Predictors of under-five childhood diarrhea: Mecha District, West Gojam, Ethiopia. Ethiop J Health Dev 25: 192-200.

6. Jamison DT, Breman JG, Measham AR, Alleyne G, Claeson M, et al. (2006) In: Disease Control Priorities in Developing Countries. Washington (DC).

7. Ahs JW, Tao W, Löfgren J, Forsberg BC (2010) Diarrheal Diseases in Lowand Middle-Income Countries: Incidence, Prevention and Management. Open Infect Dis J 4: 113-124.

8. Keusch GT, Fontaine O, Bhargava A, Boschi-Pinto C, Bhutta ZA, et al. (2006) Diarrheal Diseases In: Jamison DT, Breman JG, Measham AR, Disease Control Priorities in Developing Countries. The International Bank for Reconstruction and Development/The World Bank Group, Washington (DC) 2: 371-388.

9. WHO (2005) The Treatment of Diarrhoea: A Manual for Physicians and Other Senior Health Workers.

10. Mediratta RP, Feleke A, Moulton LH, Yifru S, Sack RB (2010) Risk factors and case management of acute diarrhoea in North Gondar zone, Ethiopia. J Health Popul Nutr 28: 253-263.

11. WHO (2017) Children: reducing mortality.

12. UN ICEF (2014) Reduce child mortality; Millennium development Goals.

13. Mengistie B, Berhane Y, Worku A (2013) Prevalence of Diarrhea and Associated Risk Factors among Children Under-Five Years of Age in Eastern Ethiopia: A Cross-Sectional Study. Open J Prev Med 3: 446-453.

14. Teklemariam S, Getaneh T, Bekele F (2000) Environmental Determinants of Diarrheal Morbidity in Under-Five Children, Keffa-Sheka Zone, South West Ethiopia. Ethiop Med J 38: 27-34.

15. Tarekegn M, Enqueselassie F (2012) A Case Control Study on Determinants of Diarrheal Morbidity among Under-Five Children in Wolaita Soddo Town, Southern Ethiopia. Ethiop J Health Dev 26: 78-85.

16. Mengistie B, Berhane Y, Worku A (2013) Household Water Chlorination Reduces Incidence of Diarrhea among Under-Five Children in Rural Ethiopia: A Cluster Randomized Controlled Trial. PLoS ONE, 8: e77887.

17. Mekasha A, Tesfahun A (2003) Determinants of Diarrhoeal Diseases: A Community Based Study in Urban South Western Ethiopia. East Afr Med J 80: 77-82.

18. Assefa N, Oljira L, Baraki N, Demena M, Zelalem D (2016) HDSS Profile: The Kersa Health and Demographic Surveillance System. Int J Epidemiol 45: 94-101.

19. Godana W, Mengistie B (2013) Environmental Factors Associated with Acute Diarrhea among Children under Five Years of Age in Derashe District, Southern Ethiopia. Sci 1: 119-124.

20. Gebru T, Taha M, Kassahun W (2013) Prevalence of Diarrheain UnderFive Children among Health Extension Model and Non-Model Households in Sheko District Rural Community, Southwest Ethiopia. Sci 1: 230-234.

21. Desalegn M, Kumie A, Tefera W (2011) Predectors of Under-Five Childhood Diarrhea: Mecha District, West Gojjam, Ethiopia. Ethiop J Health Dev 25: 174-232.

22. Berhe F, Berhane Y (2014) Under-five Diarrhea among Model Household and Non-Model Households in Hawassa, South Ethiopia: A Comparative Cross-Sectional Community. BMC Public Health 14: 187.

23. Anteneh A, Kumie A (2010) Assessment of the impact of latrine utilization on diarrhoeal diseases in the rural community of Hulet Ejju Enessie Woreda, East Gojjam Zone, Amhara Region. Ethiop. J Health Dev 24.

24. Mediratta RP, Feleke A, Moulton LH, Yifru S, Sack RB (2010) Risk Factors and Case Management of Acute Diarrhoea in North Gondar Zone, Ethiopia. J Health Popul Nutr 28: 253-263.

25. Central statistical Authority, ORC Marko (2011) Ethiopia Demographic and Health Survey. Addis Ababa Calverton Ethiopia and Maryland, USA. 
Citation: Kasye DG, Garoma NH, Kassa MA (2018) Assessment of the Prevalence of Diarrheal Disease Under-five Children Serbo Town, Jimma Zone South West Ethiopia. Clinics Mother Child Health 15: 281. doi:10.4172/2090-7214.1000281

Page 6 of 6

26. Yassin K (2000) Morbidity and risk factors of diarrheal disease among under-five children in rural Upper Egypt. J Trop Pediatr 46: 282-287.

27. Kuitunen M, Boadi KO (2005) Childhood diarrheal morbidity in the Accra Metropolitan Area, Ghana: socio-economic, environmental and behavioural risk determinants. World Health \& Population J Health Popul Dev Ctries.

28. Mihrete TS, Alemie GA, Teferra AS (2014) Determinants of childhood diarrhoea among under five children in Benishangul Gumuz Regional State, North West Ethiopia. BMC Pediatrics 14: 102.

29. Dessalegn M, Kumie A, Tefera W (2011) Predictors of under-five childhood diarrhoea: Mecha District, West Gojam, Ethiopia. Ethiop J Health Dev 1: 25.

30. Mengistie B, Berhane Y, Worku A (2013) Prevalence of diarrhoea and associated risk factors among children under-five years of age in Eastern Ethiopia. Open J Prev Med: 446-453.

31. Mohammed S, Tilahun M, Tamiru D (2013) Morbidity and Associated Factors of Diarrheal Diseases Among Under Five Children in ArbaMinch District, Southern Ethiopia. Science J Public Health 1: 102-106.

32. Dessalegn M, Kumie A, Tefera W (2011). Predictors of under-five childhood diarrhea: Mecha District, West Gojam, Ethiopia. Ethiop J Health Dev 25: 194-196.

33. Mengistie B, Berhane Y, Worku A (2013) Prevalence of diarrhoea and associated risk factors among children under-five years of age in Eastern Ethiopia: A cross-sectional study. J Prev Med 3: 446-453.

34. Central statistical Authority, ORC Marko (2011) Ethiopia Demographic and Health Survey. Addis Ababa Calverton Ethiopia and Maryland, USA.

35. Central Statistics Authority, ORC Marco (2005) Ethiopia Demographic and health survey Addis Ababa Ethiopia and Calverton, Maryland, USA 2006.

36. Central Statistics Authority, ORC Marco (2000) Ethiopia Demographic and health survey Addis Ababa Ethiopia and Calverton Maryland USA 2001.

37. Mihrete TS, Alemie GA, Teferra AS (2014) Determinants of childhood diarrhea among under-five children in Benishangul Gumuz Regional State, North West Ethiopia. BMC Pediatrics 14

38. Dessalegn M, Kumie A, Tefera W (2011) Predictors of under-five childhood diarrhea: Mecha District, West Gojam, Ethiopia. Ethiop J Health Dev 25.
39. Gebru T, Taha M, Kassahun W (2014) Risk factors of diarrheal disease in under-five children among health extension model and non-model families in Sheko district rural community, Southwest Ethiopia: comparative cross-sectional study. BMC Public Health 14: 395.

40. Siziya S, Muula AS, Rudatsikira E (2009) Diarrhea and acute respiratory infections prevalence and risk factors among under-five children in Iraq. Ital J Pediatr 35: 8.

41. Kuitunen M, Boadi KO (2005) Childhood diarrheal morbidity in the Accra Metropolitan Area, Ghana: socio-economic, environmental and behavioural risk determinants. World Health \& Population J Health Popul Dev Ctries.

42. Mohammed S, Tilahun M, Tamiru D (2013) Morbidity and associated factors of diarrheal diseases among under fvive children in Arba-Minch district, Southern Ethiopia. Sci J Public Health 1: 102-106.

43. Godana W, Mengiste B (2013) Environmental Factors Associated with Acute Diarrhea among Children Under Five Years of Age in Derashe District, Southern Ethiopia. Sci J Public Health 1: 119-124.

44. Birke WA (2008) A Stepwise regression analysis on under-five diarrheal morbidity prevalence in Nekemte town, western Ethiopia. East Afr J Public Health 5: 193-198.

45. Hashi A, Kumie A, Gasana J (2016) Prevalence of Diarrhea and Associated Factors among Under-Five Children in Jigjiga District, Somali Region, Eastern Ethiopia. Open J Prev Med 233-246.

46. Katharina D, Patrik T, Jochen R, Michael M (2014) Diarrhea prevalence in under five years of age in rural Burundi: an assessment of social and behavioural factors at the household level. Glob Health Action 7.

47. Godana W, Mengistie B (2013) Environmental Factors Associated with Acute Diarrhea among Children under Five Years of Age in Derashe District, Southern Ethiopia. Sci 1: 119-124.

48. Regassa G (2008) Environmental determinants of diarrhea among under fve children in Nekemte town, western Ethiopia. Ethiop J Health Sci 18: $39-45$.

49. Osumanu IK (2007) Household environmental and behavioural determinants of childhood diarrhoea morbidity in the Tamale Metropolitan Area (TMA), Ghana. Danish J Geo 107: 59-68. 